\title{
Endocannabinoid 2-arachidonoylglycerol self-administration by Sprague-Dawley rats and stimulation of in vivo dopamine transmission in the nucleus accumbens shell
}

\section{Maria Antonietta De Luca ${ }^{1,2}{ }^{*}$, Valentina Valentini ${ }^{1,2,3}$, Zisis Bimpisidis ${ }^{1}$, Fabio Cacciapaglia ${ }^{1}$, Pierluigi Caboni ${ }^{4}$ and Gaetano Di Chiara ${ }^{1,2,3,5}$}

${ }^{1}$ Neuropsychopharmacology Section, Department of Biomedical Sciences, University of Cagliari, Cagliari, Italy

${ }^{2}$ National Institute of Neuroscience (INN), Cagliari, Italy

${ }^{3}$ Centre of Excellence for Studies on the Neurobiology of Addiction, Cagliari, Italy

${ }^{4}$ Department of Life and Environmental Sciences, University of Cagliari, Cagliari, Italy

${ }^{5}$ Cagliari Section, Neuroscience Institute, National Research Council of Italy, Cagliari, Italy

\section{Edited by:}

Steven R. Laviolette, University of Western Ontario, Canada

\section{Reviewed by:}

Mariela Fernanda Perez, Universidad Nacional de Cordoba, Argentina Olivier George, The Scripps Research Institute, USA

\section{*Correspondence:}

Maria Antonietta De Luca,

Neuropsychopharmacology Section, Department of Biomedical Sciences, University of Cagliari, Via Ospedale 72, Cagliari 09124, Italy e-mail:deluca@unica.it
2-Arachidonoylglycerol (2-AG) is the most potent endogenous ligand of brain cannabinoid $\mathrm{CB}_{1}$ receptors and is synthesized on demand from 2-arachidonate-containing phosphoinositides by the action of diacylglycerol lipase in response to increased intracellular calcium. Several studies indicate that the endocannabinoid (eCB) system is involved in the mechanism of reward and that diverse drugs of abuse increase brain eCB levels. In addition, eCB are self-administered (SA) by squirrel monkeys, and anandamide increases nucleus accumbens (NAc) shell dopamine (DA) in rats. To date, there is no evidence on the reinforcing effects of 2-AG and its effects on DA transmission in rodents. In order to fill this gap, we studied intravenous 2-AG SA and monitored the effect of 2-AG on extracellular DA in the $\mathrm{NAc}$ shell and core via microdialysis in male Sprague-Dawley rats. Rats were implanted with jugular catheters and trained to self-administer 2-AG [25 mg/kg/inf intravenously (iv)] in single daily $1 \mathrm{~h}$ sessions for 5 weeks under initial fixed ratio (FR) 1 schedule. The ratio was subsequently increased to FR2. Active nose poking increased from the 6th SA session (acquisition phase) but no significant increase of nose pokes was observed after FR2. When 2-AG was substituted for vehicle (25th SA session, extinction phase), rate responding as well as number of injections slowly decreased. When vehicle was replaced with 2-AG, SA behavior immediately recovered (reacquisition phase). The reinforcing effects of 2-AG in SA behavior were fully blocked by the CB1 receptor inverse agonist/antagonist rimonabant (1 mg/kg intraperitoneally, $30 \mathrm{~min}$ before SA session). In the microdialysis studies, we observed that 2-AG $(0.1-1.0 \mathrm{mg} / \mathrm{kg}$ iv) preferentially stimulates NAc shell as compared to the NAc core. NAc shell DA increased by about $25 \%$ over basal value at the highest doses tested $(0.5$ and $1.0 \mathrm{mg} / \mathrm{kg}$ iv). The results obtained suggest that the eCB system, via 2-AG, plays an important role in reward.

Keywords: endocannabinoids, 2-arachidonoilglycerol, self-administration, reward, drug addiction, in vivo microdialysis, nucleus accumbens

\section{INTRODUCTION}

Endocannabinoid (eCB) signaling controls various central functions in mammals, such as nociception, feeding, energy homeostasis, mood, learning, memory, growth, development, and reward processes (1-6). The eCB system consists of cannabinoid receptors (CB1 and CB2), lipid-derived endogenous ligands $[N$ arachidonoylethanolamine or anandamide, 2-arachidonoylglycerol

Abbreviations: 2-AG 2-arachidonoylglycerol; DA, dopamine; eCB, endocannabinoids; HPLC, high performance liquid chromatography; HPLC-MS/MS, high performance liquid chromatography-mass spectrometry; ip, intraperitoneally; iv, intravenously NAc, nucleus accumbens; SA, self-administration.
$(2-A G)]$, and specific enzymes involved in the biosynthesis and degradation of eCB.

Many questions on eCB signaling still need to be answered. However, among the two endogenous ligands, anandamide and 2-AG, 2-AG appears to be the most potent endogenous ligand for brain cannabinoid $\mathrm{CB}_{1}$ receptors (7). 2-AG acts as a full agonist of $\mathrm{CB} 1$ and $\mathrm{CB} 2$ receptors (8-10), and is synthesized on demand from 2-arachidonate-containing phosphoinositides by the action of diacylglycerol lipase (DAGL $\alpha$ and DAGL $\beta$ ) in response to elevations of intracellular calcium. Unlike classic neurotransmission systems (e.g., monoaminergic, cholinergic, aminoacidergic), 2AG signaling in the nervous system takes place in a retrograde fashion. Thus, stimulation of the postsynaptic neuron induces 
the biosynthesis of 2-AG that thus diffuses to the presynaptic terminal to act on $\mathrm{CB} 1$ receptors; due to its lipophilic nature, no synaptic vesicles for storage of $2-A G$ exist $(4,11,12)$. Given these characteristics, 2-AG is considered to be a neuromodulator rather than a transmitter. $\mathrm{CB} 1$ activation of $\mathrm{G}_{\mathrm{i} / \mathrm{o}}$ proteins inhibits neurotransmission but the net inhibitory or excitatory effect of 2-AG signaling depends on the type of neurons involved in the process $(4,13-16)$. 2-AG is mainly degraded by monoacylglycerol lipase (MAGL), a membrane-associated, cytoplasm-facing soluble enzyme located pre-synaptically at axon terminals along with the $\mathrm{CB} 1$ receptor (17-19). Furthermore, about $15 \%$ of $2-\mathrm{AG}$ is hydrolyzed by ABHD6 and ABHD12, and the remaining 1-2\% by fatty acid amide hydrolase (FAAH) (20). The mechanisms of 2-AG neuronal reuptake are not completely known, but putative transporters have been described $(3,21)$.

Drugs of abuse affect brain eCB levels and it has been proposed that the activation of the eCB system is involved in many aspects of addiction (22). Drug-induced increases in eCB synthesis play a role in drug reward, and it has been suggested that $\mathrm{eCBs}$ are involved in long-term synaptic plasticity of neural substrates of motivation and reward in relation to addiction (23).

In human beings, a genetic disruption of eCB clearance is associated with drug abuse $(24,25)$. CB1 receptor activation affects the addictive properties of opioids, cocaine, alcohol, and nicotine (26). On the other hand, $\mathrm{CB}_{1} \mathrm{KO}$ mice show reduced ethanol and morphine self-administration (SA) and attenuated ethanoland opiate-induced place conditioning (27-29). In rats, the $\mathrm{CB}_{1}$ receptor inverse agonist/antagonist SR-141716A (Rimonabant) reduces ethanol and opiate SA (30-32) while in mice it reverses the behavioral and neurochemical effects of cocaine (33).

$\Delta$ 9-Tetrahydrocannabinol (THC), the main active component of marijuana, is known to reduce the severity of opioid withdrawal in human beings and rodents, and acute inhibition of FAAH or MAGL alleviates symptoms of precipitated and spontaneous withdrawal in opioid- and THC-dependent mice $(34,35)$. The eCB system is involved in the rewarding effects of THC (22), as well as ethanol and opiates $(36,37)$. In particular, ethanol and heroin SA increases eCB levels in the nucleus accumbens (NAc) shell, suggesting a role for NAc eCB transmission in the reinforcing effects produced by these drugs (38). Finally, eCBs are SA by squirrel monkeys, meaning that they are effective reinforcers of drug-taking behavior $(39,40)$.

Dopamine (DA) neurotransmission is known to regulate a large number of motivated and addiction-related behaviors (41-43). Importantly, drugs of abuse of the most diverse pharmacological classes increase mesolimbic DA transmission in rats as well as in human beings preferentially or, depending on doses and conditions, selectively in the ventral striatum/NAc (42, 44-48). Accordingly, THC and the synthetic cannabinoid WIN 55,2122 increase extracellular DA concentrations in the shell, but not in the core of the NAc, both when injected intravenously (iv) (49) and when SA by different strains of rats $(50,51)$. In addition, anandamide increases NAc shell DA and its effect is amplified by the FAAH inhibitor, URB597 (52). On the other hand, reduced DA transmission in the mesolimbic system is associated with spontaneous or rimonabant-precipitated THC withdrawal $(53,54)$.
In spite of this extensive literature, no studies are available on the reinforcing effects of 2-AG and its effects on DA transmission in rodents. In order to fill this gap, we studied intravenous 2-AG SA and monitored the effect of 2-AG on extracellular DA in the NAc shell and core via microdialysis in male Sprague-Dawley rats.

\section{MATERIALS AND METHODS ANIMALS}

Male Sprague-Dawley rats (Harlan, Italy), weighting 250-275 g upon arrival, were housed four per cage given ad libitum access to food and water in a temperature $\left(22^{\circ} \mathrm{C}\right)$ and humidity $(60 \%)$ controlled vivarium with a $12 \mathrm{~h}$ light/dark cycle (on 08:00 A.M., off 08:00 P.M.). After surgery (catheter implantation), rats were individually housed in plastic cages $(30 \mathrm{~cm} \times 20 \mathrm{~cm} \times 20 \mathrm{~cm})$ given ad libitum food and water access, and in the same environmental conditions. For 7-10 days before surgery, rats were handled twice a day. SA sessions were performed during the light phase, between 9:00 a.m. and 5:00 p.m. After the experimental sessions, the rats were returned to their home cages where a daily ration of $18 \mathrm{~g}$ of food was made available, which maintained body weights at stable levels throughout these studies. The weight of rats at the beginning of SA studies was 300-325 g. Rats were weighed every day for the duration of the SA experiments. No significant reduction of body weight was observed. All experimental procedures met the guidelines and protocols approved by Italian (D.L. 116/92 and 152/06) and European Council directives $(609 / 86$ and 63/2010) and in compliance with the approved animal policies by the Ethical Committee for Animal Experiments (CESA, University of Cagliari) and the Italian Ministry of Health.

\section{DRUGS}

The eCB 2-AG was purchased from Tocris Cookson Ltd. (Northpoint, UK) and was dissolved in a vehicle containing $2 \%$ ethanol, $2 \%$ Tween 80 , and saline and administered as an intravenous bolus of $20 \mu \mathrm{l}$ for SA studies $(12.5,20,50 \mu \mathrm{g} / \mathrm{kg} /$ infusion $)$ or $1 \mathrm{ml} / \mathrm{kg}$ solution for microdialysis studies $(0.1-1 \mathrm{mg} / \mathrm{kg}$ iv).

The CB1 receptor inverse agonist/antagonist rimonabant (SR141716A) was obtained from Sigma (RD-Sigma, Italy) and suspended in $0.3 \%$ Tween 80 and saline. It was administered $(1 \mathrm{mg} / \mathrm{kg}$ intraperitoneally, ip) $30 \mathrm{~min}$ prior to 2 -AG SA sessions.

\section{2-AG SOLUTIONS}

2-Arachidonoylglycerol content in the solutions prepared for SA or microdialysis studies was determined by HPLC-MS/MS analysis performed on MAX-RP C18 column $(150 \times 4.60 \mathrm{~mm} ; 4 \mu \mathrm{m})$. The samples $(20 \mu \mathrm{L})$ were analyzed by ESI in positive SIM mode following the ion $[\mathrm{M}+\mathrm{H}]^{+} 379 \mathrm{~m} / z$. The HPLC conditions were as follows: flow rate: $0.4 \mathrm{ml} / \mathrm{min}$; solvent $\mathrm{A}: 0.1 \%$ formic acid in water; solvent B: acetonitrile; and gradient: solvent B 5-100\% over $10 \mathrm{~min}$. The samples $(20 \mu \mathrm{l})$ were then analyzed by a Varian 1200 triple quadrupole HPLC-MS. Mass spectral data were acquired with a scan time of $1.0 \mathrm{~s}$, needle $3500 \mathrm{~V}$, shield $600 \mathrm{~V}$, capillary $30 \mathrm{~V}$, and detector $1900 \mathrm{~V}$. The source parameters were adjusted as follows: drying gas temperature $250^{\circ} \mathrm{C}$, drying gas pressure $20 \mathrm{psi}$, and nebulizer pressure 45 psi. 


\section{SELF-ADMINISTRATION STUDIES}

Daily SA sessions were carried out in chambers housed in soundproof boxes (Coulbourn Instruments, Allentown, NJ, USA) containing two nose-poke holes, one active and the other inactive. A yellow/green light was placed over the active hole and a red light over the inactive one as discriminative stimuli. Prior to each daily session, the jugular catheter was flushed with $0.1 \mathrm{ml}$ of sterile saline and the rats were placed in the SA box.

Rats were anesthetized with Equitesin ( $3 \mathrm{ml} / \mathrm{kg}$ ip; chloral hydrate $2.1 \mathrm{~g}$, sodium pentobarbital $0.46 \mathrm{~g}, \mathrm{MgSO}_{4} 1.06 \mathrm{~g}$, propylene glycol $21.4 \mathrm{ml}$, ethanol $(90 \%) 5.7 \mathrm{ml}, \mathrm{H}_{2} \mathrm{O} 3 \mathrm{ml}$ ) and implanted in the right jugular vein with a catheter, consisting of medical-grade tubing (Silastic, Dow Corning Corporation, Michigan, USA) according to the technique previously described (50). A stable fixation in the mid-scapular region of the back was embedded by a polypropylene mesh (Evolution, BULEV, weight $48 \mathrm{~g} / \mathrm{mq}$, Dipromed, Italy). During the recovery period, at least 7 days after surgery, the catheters were flushed daily with $0.1 \mathrm{ml}$ of gentamicin $(40 \mathrm{mg} / \mathrm{ml})$ and with heparinized saline (heparin $250 \mathrm{U} / \mathrm{ml}$ in $0.9 \%$ sterile saline).

Ten days after recovery from surgery, 13 rats were trained to SA 2-AG $(25 \mu \mathrm{g} / \mathrm{kg} / 20 \mu \mathrm{l}$, iv) in $1 \mathrm{~h}$-daily sessions ( 5 days/week) for 13 consecutive sessions, according to a FR 1 schedule of reinforcement (FR 1, 1 nose poke: 1 injection). During the third week, when all rats had fulfilled the criterion of $85 \%$ responses in the active hole and stable responding over three sessions, the schedule of reinforcement was increased to FR 2 (2:1) (14th-24th session). A nose poke in the active hole resulted in a 4-s infusion of 2-AG. Each 2-AG infusion was followed by a 20-s time-out period, during which further nose pokes were recorded but did not result in additional intravenous infusions. Rats were also studied in the extinction phase from the 25th session, when the $2-A G$ solution was substituted with vehicle (25th-32nd day of administration). A group of six rats were also studied in reacquisition when vehicle was replaced with 2-AG (33th-40th). Another group of animals were used to study the effect of varying injection doses of 2-AG. At the end of each SA session, the catheters were flushed with $0.1 \mathrm{ml}$ of heparinized saline. The responses performed by each rat on both holes for the entire 1-h daily session and the corresponding number of reinforces received was recorded (Graphic State 2 software, Coulbourn instruments, PA, USA).

\section{MICRODIALYSIS STUDIES}

Rats were anesthetized with Equitesin ( $3 \mathrm{ml} / \mathrm{kg}$ ip), prepared as previously described, and placed in a stereotaxic apparatus. The skull was exposed, and a small hole was drilled on one side. The probe was implanted vertically in the NAc shell $(\mathrm{A}+2.2 ; \mathrm{L}+1.0$ from bregma; $\mathrm{V}-7.8$ from dura) or in the NAc core $(\mathrm{A}+1.4 ; \mathrm{L}+1.6$ from bregma; V-7.6 from dura) according Paxinos and Watson (55), and then fixed on the skull with dental cement. Rats were housed in transparent plastic (Plexiglas) hemispheric bowls with food and water available. Experiments were performed on freely moving rats $24 \mathrm{~h}$ after probe implantation. A Ringer's solution ( $147 \mathrm{mM}, \mathrm{NaCl} ; 2.2 \mathrm{mM}, \mathrm{CaCl} 2 ; 4 \mathrm{mM}, \mathrm{KCl}$ ) was pumped through the dialysis probe at a constant rate of $1 \mu \mathrm{l} / \mathrm{min}$. Dialysate samples $(10 \mu \mathrm{l})$ were taken every $10 \mathrm{~min}$ and injected without purification into an HPLC apparatus equipped with a reverse-phase column (C8 $3.5 \mu \mathrm{m}$, Waters, Mildford, MA, USA) and a coulometric detector (ESA Coulochem II, Bedford, MA, USA) to quantify DA. The first electrode of the detector was set at $+130 \mathrm{mV}$ (oxidation) and the second at $-175 \mathrm{mV}$ (reduction). The composition of the mobile phase was $50 \mathrm{mM} \mathrm{NaH}_{2} \mathrm{PO}_{4}, 0.1 \mathrm{mM} \mathrm{Na} 2$-EDTA, $0.5 \mathrm{mM} n$-octyl sodium sulfate, and $15 \%(\mathrm{v} / \mathrm{v})$ methanol, $\mathrm{pH} 5.5$. The sensitivity of the assay for DA was $5 \mathrm{fmol} / \mathrm{sample}$.

At the end of the experiment, animals were sacrificed and their brains were removed and stored in formalin (8\%) before histological analysis. To this end, brains were cut on a vibratome in serial coronal slices $(20 \mu \mathrm{m})$ oriented according to Paxinos and Watson (55) to locate the placement of the microdialysis probe.

\section{DATA ANALYSIS}

Nose pokes emitted during each 1-h 2-AG SA session during acquisition and extinction phases were analyzed by two-way repeated measures ANOVA with nose pokes (i.e., active vs inactive) and days as within subject factors. Reacquisition was analyzed by two-way ANOVA, with nose pokes (i.e., active vs inactive) and days with respect to the corresponding final 2-AG session (i.e., 32nd 2-AG SA session) as within subject factors. Where significant effects were obtained by ANOVA; LSD post hoc tests were performed.

Repeated measures ANOVA was applied to the data obtained from the serial assays of DA after each treatment. Results from treatments showing significant overall changes were subjected to post hoc Tukey tests with significance for $p<0.05$. Basal values were the means of three consecutive samples differing less than $10 \%$.

\section{RESULTS}

\section{SELF-ADMINISTRATION STUDIES}

Experiment 1: acquisition, extinction, and reacquisition of 2-AG self-administration

In this experiment, acquisition, extinction, and reacquisition of 2-AG SA were studied. Figure 1A shows that rats implanted with a jugular catheter were trained to SA $2-A G(25 \mu \mathrm{g} / \mathrm{kg} / 20 \mu \mathrm{l}$ infusion, unit dose) in a single daily $1 \mathrm{~h}$ session, under an initial FR (FR) 1 schedule, which was then increased to FR2. Figure 1A also shows the average number of active and inactive nose pokes performed by rats trained on 2-AG SA during acquisition, extinction, and reacquisition phases. Two-way ANOVA of acquisition and extinction phases showed a significant effect of nose pokes $\left(F_{1,24}=3.466\right.$; $p<0.0001)$, and of sessions $\left(F_{31,744}=182.97 ; p<0.0001\right)$ and a significant nose pokes $\times$ session interaction $\left(F_{31,744}=214.069\right.$; $p<0.0001)$. LSD post hoc tests showed significant differences between active vs inactive nose pokes from the 7th to the 29th 2-AG SA session. Two-way ANOVA of reacquisition, applied from the period 32nd to 40th session, showed a main effect of active vs passive nose pokes $\left(F_{1,10}=1381.47 ; p<0.01\right)$. LSD post hoc tests showed significant differences between active and inactive nose pokes from the 33rd to the 40th 2-AG SA session. No differences were observed in active nose poking on each Monday following the weekend abstinence compared with the last session of the preceding week. The percentage of rats that acquired 2-AG SA was $90 \%$.

Figure 1B shows the daily intake $(\mu \mathrm{g} / \mathrm{kg})$ of $2-A G$ or vehicle during all phases of SA (left $Y$-axis) and the corresponding number of reinforcements obtained (right $Y$-axis) in each 1-h session under a FR 1 or FR 2 schedule from rats that acquired 2-AG SA. 

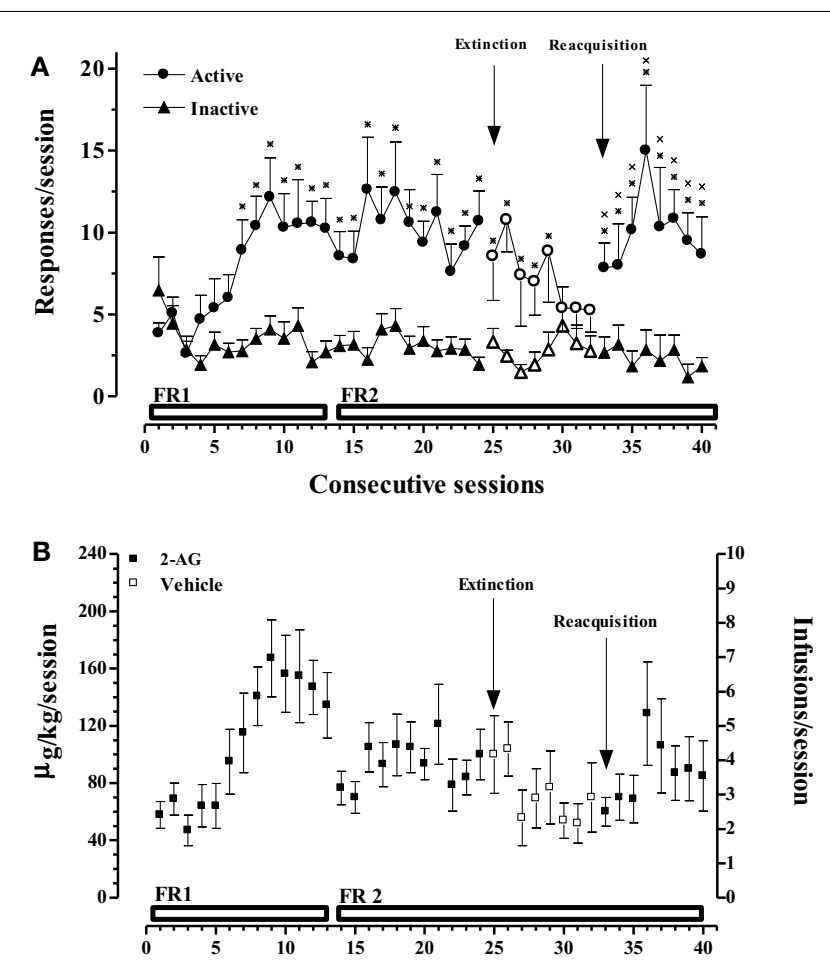

Consecutive sessions

C

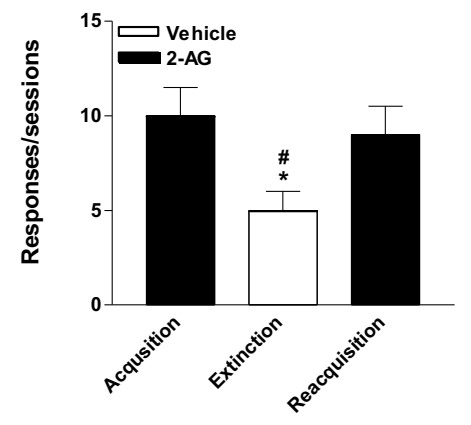

FIGURE 1 | Acquisition, extinction, and reacquisition of 2-AG self-administration (SA) behavior over consecutive session.

(A) Number of responses (nose pokes) for 2-AG SA (25 $\mu \mathrm{g} / \mathrm{kg} /$ infusion). Results are expressed as mean \pm SEM of nose pokes in the active (circle) and inactive (triangle) holes during each 1-h daily session under FR 1 and FR 2 schedule (acquisition phase: 1st-24th days, filled symbols, $N=13$; extinction phase: $25 \mathrm{st}-32 \mathrm{nd}$ days, open symbols, $N=13$; reacquisition phase: 33 th-40th days, filled symbols; $N=6$ ). ${ }^{*} p<0.05$ vs inactive nose pokes; ANOVA followed by LSD post hoc test. (B) Daily intake and number of infusions during 2-AG SA. Data are expressed as $\mu \mathrm{g} / \mathrm{kg}$ (left $Y$-axis) or number of infusions (right $Y$-axis) of 2-AG during each 1-h daily session (1st-24th; 33th-40th, filled squares) or vehicle (25th-32nd, open squares). (C) Number of responses during each phase of 2-AG SA. Each bar represents the mean $\pm S E M$ of the last three sessions under acquisition, extinction, and reacquisition phases of 2 -AG SA. ${ }^{*} p<0.05$ vs acq.; ${ }^{\#} p<0.05$ vs reacq. ANOVA followed by LSD post hoc test.

Figure 1C shows the mean number of responses during the last three sessions of acquisition, extinction, and reacquisition phases. One-way ANOVA showed a main effect of the different SA phases $\left(F_{2,15}=7.81 ; p<0.05\right)$. LSD post hoc tests showed significant differences between extinction and acquisition or reacquisition.

\section{Experiment 2: effect of dose of 2-AG and CB1 receptor blockade on 2-AG SA}

In the second experiment, the effects of varying doses of 2AG $(12.5-50 \mu \mathrm{g} / \mathrm{kg} / 20 \mu \mathrm{l}$ infusion, unit dose) and rimonabant (SR-141716A, $1 \mathrm{mg} / \mathrm{kg}$ ip, $30 \mathrm{~min}$ before SA session) under an FR1 schedule were studied (Figures 2A,B). Two-way ANOVA of acquisition at the dose of $25 \mu \mathrm{g} / \mathrm{kg} /$ infusion showed a significant effect of nose pokes $\left(F_{1,24}=3.896 ; p<0.0001\right)$ and of sessions $\left(F_{15,360}=324.115 ; p<0.0001\right)$, and a significant nose poke $\times$ session interaction $\left(F_{15,360}=316.965 ; p<0.0001\right)$. LSD post hoc tests showed significant differences between active and inactive nose pokes $(7,10,12,13$, and 15th SA session). Twoway ANOVA of acquisition at the dose of $12.5 \mu \mathrm{g} / \mathrm{kg} /$ infusion showed a main effect of active vs passive nose pokes $\left(F_{1,15}=1.45\right.$, $p<0.001)$. LSD post hoc tests showed significant differences between active and inactive nose pokes (18, 20th 2-AG SA session). Two-way ANOVA of acquisition at the dose of $50 \mu \mathrm{g} / \mathrm{kg} /$ infusion showed a main effect of active vs passive nose pokes $\left(F_{1,15}=8.25\right.$; $p<0.01)$. LSD post hoc tests showed significant differences between active and inactive nose pokes $(29,30,38-40$ th $2-A G$ SA session). Two-way ANOVA of acquisition at the dose of $50 \mu \mathrm{g} / \mathrm{kg} /$ infusion after rimonabant injection showed a significant main effect of active vs passive nose pokes $\left(F_{1,9}=6.22\right.$; $p<0.05)$ and of day $\left(F_{2,8}=2.19 ; p<0.05\right)$. LSD post hoc tests showed significant differences between active and inactive nose pokes (37-40th 2-AG SA session).

Figure 2B shows the mean number of responses during the last three sessions of 2-AG SA at the dose of $50 \mu \mathrm{g} / \mathrm{kg} /$ infusion (29-31st 2-AG SA session) and the effect of rimonabant pre-treatment (SR, $1 \mathrm{mg} / \mathrm{kg}$ ip, $30 \mathrm{~min}$ before each session) for two consecutive sessions (32nd and 33rd 2-AG SA session). One-way ANOVA showed a main effect of the different SA phases $\left(F_{2,21}=9.91 ; p<0.05\right)$. LSD post hoc tests showed significant differences between groups.

Figure 3 shows that varying the injection dose of 2-AG resulted in a classic inverted-U-shape dose-response curve. One-way ANOVA showed that 2-AG maintained significantly higher numbers of infusions per session $\left(F_{3,8}=12.44 ; p<0.01\right)$ (Figure 3A) and higher rates of responding $\left(F_{3,8}=45.75\right.$; $p<0.001$ ) (Figure 3B) than vehicle at the doses of $12.5,25$, and $50 \mu \mathrm{g} / \mathrm{kg} /$ infusion. LSD post hoc tests showed that the maximal rate of responding $(0.12 \pm 0.09$ response/s $)$ and the number of injections per session ( $7 \pm 1.19$ injections/session) were maintained by $25 \mu \mathrm{g} / \mathrm{kg} 2-\mathrm{AG} /$ infusion. The highest $2-\mathrm{AG}$ intake per session was reached at a dose of $50 \mu \mathrm{g} / \mathrm{kg} /$ injection $(155 \pm 0.40 \mu \mathrm{g} / \mathrm{session})$ (Figure 3C).

\section{MICRODIALYSIS STUDIES}

\section{Effect of 2-AG administration on dopamine transmission in the NAc} shell and core

Basal values of DA, expressed as fmoles $/ 10 \mathrm{ml}$ sample $($ mean \pm SEM), were NAc shell $52 \pm 5(N=19)$ and NAc core $54 \pm 4(N=12)$.

Figure 4 shows that 2-AG $(0.1-1.0 \mathrm{mg} / \mathrm{kg}$ iv $)$ preferentially stimulated the NAc shell with respect to the NAc core DA. The 

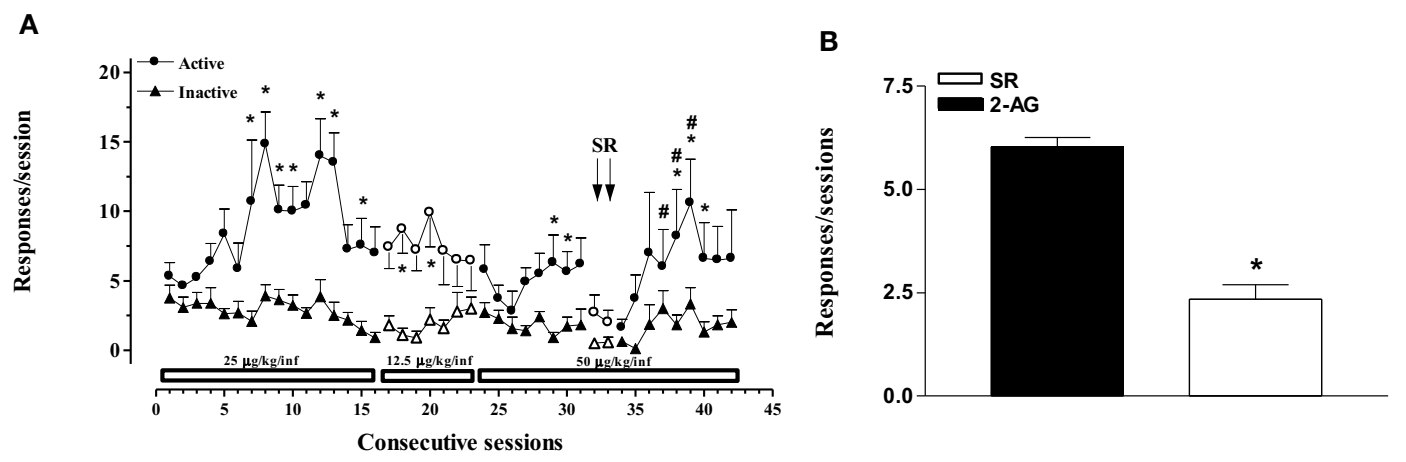

FIGURE 2 | 2-Arachidonoylglycerol self-administration (SA) behavior at different 2-AG doses and effect of $C B 1$ receptor blockade on SA.

(A) Number of responses (nose pokes) for 2-AG SA at varying 2-AG doses $(12.5,25$, and $50 \mu \mathrm{g} / \mathrm{kg})$ and effect of SR-141716A $(1 \mathrm{mg} / \mathrm{kg}, 30 \mathrm{~min}$ before sessions) on SA. Results are expressed as mean \pm SEM of cumulative nose pokes in the active (circle) and inactive (triangle) nose pokes during each 1 -h daily session of $2-A G$ SA: $25 \mu \mathrm{g} / \mathrm{kg}$ (1st-16th day); $12.5 \mu \mathrm{g} / \mathrm{kg}$ (17th-23rd day); and $50 \mu \mathrm{g} / \mathrm{kg}$ (24th-43rd day), $N=16 .{ }^{*} p<0.05$ vs inactive nose pokes; \# $p<0.05$ vs SR. ANOVA followed by LSD post hoc test. (B) Number of responses during 2-AG SA and effect of SR-141716A on SA. Bars represent the mean \pm SEM of the last three sessions under $2-A G$ SA $(50 \mu \mathrm{g} / \mathrm{kg} / \mathrm{inf})$ condition (black bar) and under SR pre-treatment condition for two consecutive session (SR, $1 \mathrm{mg} / \mathrm{kg}$ ip, $30 \mathrm{~min}$ before each session) (white bar). ${ }^{*} p<0.05$ vs veh; ${ }^{*} p<0.05$ vs SR-50. ANOVA followed by LSD post hoc test.

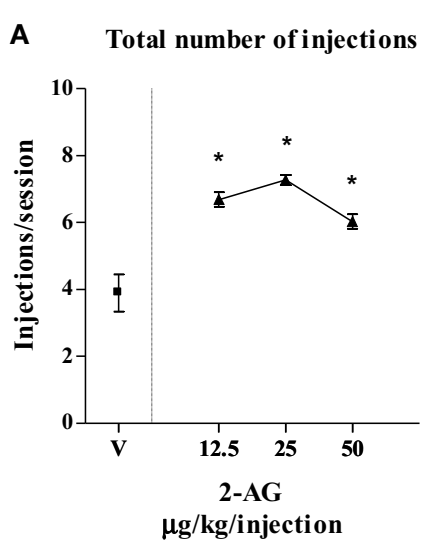

FIGURE 3 | Effect of varying injection dose on self-administration (SA) of 2-AG. (A) Total number of injections of 2-AG $(0,12.5,25$, and $50 \mu \mathrm{g} / \mathrm{kg} / \mathrm{inf})$, (B) overall rate of responding for $2-A G$, and (C) total 2-AG intake as shown as a function of injection dose of drug 10 ,

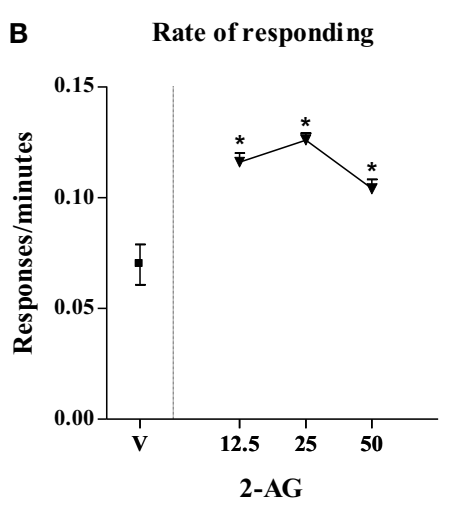

$\mu \mathrm{g} / \mathrm{kg} / \mathrm{injection}$

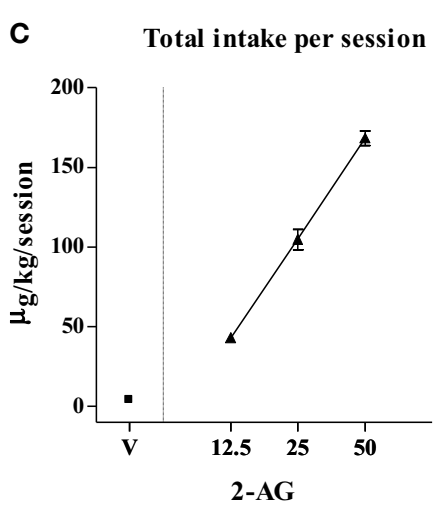

$\mu \mathrm{g} / \mathrm{kg} / \mathrm{injection}$
NAc shell DA increase was observed only at the higher doses tested ( 0.5 and $1.0 \mathrm{mg} / \mathrm{kg}$ iv) and was about $25 \%$ over basal value. Oneway ANOVA of the $0.5 \mathrm{mg} / \mathrm{kg}$ dose showed a main effect of group $\left(F_{12,48}=3.27 ; p<0.001\right)$. Tukey post hoc tests revealed differences at the $20 \mathrm{~min}$ sample with respect to basal value and to vehicle. One-way ANOVA of the $1.0 \mathrm{mg} / \mathrm{kg}$ dose showed a main effect of group $\left(F_{12,48}=2.17 ; p<0.05\right)$. Tukey post hoc tests revealed differences at the $20 \mathrm{~min}$ sample with respect to vehicle and with respect to basal value. Three way ANOVA of DA release of the NAc shell and core implanted animals revealed a significant effect of dose $\left(F_{3,23}=4.9 ; p<0.001\right)$ and a significant area $\times$ time interaction $\left(F_{12,276}=4.9 ; p<0.05\right)$.

\section{DISCUSSION}

In the present study, we demonstrate for the first time that the eCB 2-AG is SA by Sprague-Dawley rats and stimulates
$12.5,25$, and $50 \mu \mathrm{g} / \mathrm{kg}$ ). Each point represents the mean \pm SEM of the last three sessions under each 2-AG unit dose condition and under vehicle condition, $N=16$. ${ }^{*} p<0.05$ post hoc comparison vs veh (V).
DA transmission preferentially in the NAc shell as compared to the core. Hence, 2-AG possesses behavioral and DA releasing properties similar to those of food and drug rewards.

Initially, animals acquired 2-AG SA $(25 \mu \mathrm{g} / \mathrm{kg} / 20 \mu \mathrm{l}$ infusion, unit dose) in single daily $1 \mathrm{~h}$ FR 1 sessions for 5 weeks, which was then increased to FR2, under food restriction that maintained body weights at stable levels throughout these studies. Active nose pokes significantly increased over inactive nose pokes from the 6th SA session (acquisition phase), but no significant increase of nose pokes was observed under FR2. When 2-AG was replaced by vehicle (25th SA session, extinction phase), the responding rate as well as the number of injections slowly decreased. When the vehicle was replaced once again with $2-\mathrm{AG}, \mathrm{SA}$ behavior immediately recovered (reacquisition phase) (Figures 1A,C). In a second experiment, the effect of dose of $2-\mathrm{AG}(12.5,25,50 \mu \mathrm{g} / \mathrm{kg} / 20 \mu \mathrm{l}$ infusion, unit dose) and the CB1 receptor-dependent SA behavior was assessed. 


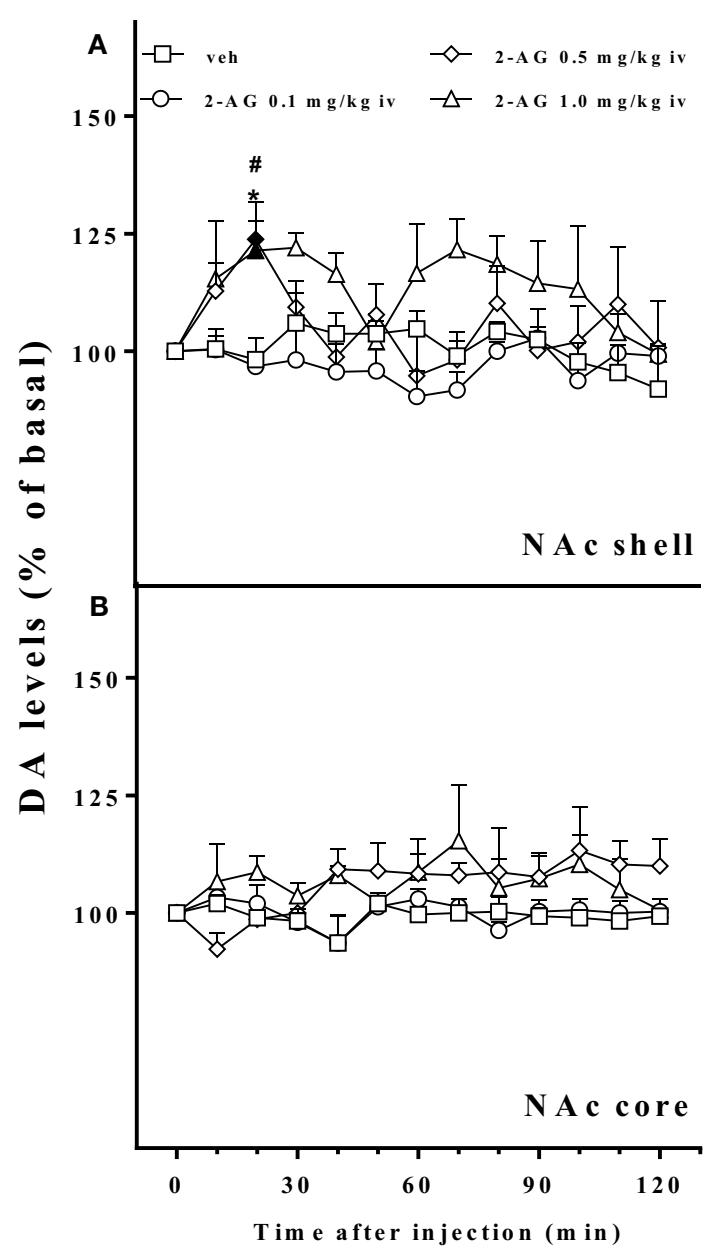

FIGURE 4 | Effect of 2-AG injection on nucleus accumbens dialysate dopamine. Effect of 2-AG $(0.1,0.5$, and $1 \mathrm{mg} / \mathrm{kg}$ iv) on NAc shell $(\mathbf{A})$ and core $(\mathbf{B})$ dialysate DA. Data are expressed as means $( \pm S E M)$ of change in DA extracellular levels expressed as a percentage of basal values. Solid symbols: $p<0.05$ with respect to basal values; ${ }^{*} p<0.05$ vs veh group; ${ }^{\#} p<0.05$ vs 0.1 group.

Different doses of 2-AG showed a tendency toward a classic inverted-U-shape dose-response curve, although non-significant differences were observed between the $25 \mu \mathrm{g} / \mathrm{kg}$ dose and the other doses tested (Figure 3). The reinforcing effects of 2-AG in SA behavior were fully blocked by the administration of the CB1 receptor inverse agonist/antagonist SR-141716A (rimonabant, $1 \mathrm{mg} / \mathrm{kg}$ ip, $30 \mathrm{~min}$ before SA session) (Figure 2B). The average number of responses during each 2-AG SA session, however, was lower in the present study than the responses (either nose pokes or lever pressing) observed during SA studies using other cannabinoids or other common drugs of abuse. Thus, rats trained to SA WIN 55-212 $(50,56)$, nicotine $(57,58)$, cocaine $(59$, $60)$, or heroin $(56,61,62)$ maintained higher rates of responding than what we observed for 2-AG SA. Nevertheless, our data are in agreement with a previous study showing that $2-\mathrm{AG}$ is iv SA by non-human primates with either anandamide or nicotine SA history (40). Justinova et al. (40), however, observed that in squirrel monkeys the rate of responding maintained by 2-AG injections was similar to those observed in THC, anandamide, methanandamide, or cocaine SA studies $(39,63-65)$. In contrast with Justinova et al. (40), our experiments were carried out in naive animals. Thus, our findings indicate that $2-A G$ serves as an effective reinforcer and that its reinforcing properties are not dependent on previous SA of other drug reinforcers.

A second group of naive rats was used to estimate the neurochemical rewarding properties of 2-AG. Thus, 2-AG administered iv at 0.5 and $1.0 \mathrm{mg} / \mathrm{kg}$ doses was able to stimulate extracellular DA release preferentially in the NAc shell as compared to the core. The increase of DA in the NAc shell was about $25 \%$ over basal value, peaking at $20 \mathrm{~min}$ after the injection of $2-\mathrm{AG}$. DA stimulation in this area was absent after the lowest dose tested $(0.1 \mathrm{mg} / \mathrm{kg}$ iv), and the DA levels were comparable to those after vehicle injections. Interestingly, the higher dose tested $(1.0 \mathrm{mg} / \mathrm{kg}$ iv $)$ elicited a biphasic DA response with a second rise in DA levels $60 \mathrm{~min}$ after 2-AG injection. Notably, our data show for the first time that 2-AG stimulates DA neurotransmission in the mesolimbic DA system. This feature is a common characteristic of all the drugs abused by human beings and it is believed to be crucial in the activation of brain rewarding pathways $(66,67)$, to be an anticipatory message for rewarding events (41) and to promote incentive learning (68) specially the DA increase in the NAc shell (42). This 2-AGdependent increase of DA in the NAc shell most likely does not depend on the direct activation of DA neurons in the VTA, but, as in the case of THC and other cannabinoid agonists, is determined by the activation of $\mathrm{CB} 1$ receptors located on presynaptic glutamatergic and/or GABAergic terminals onto VTA DA neurons (69-71).

Previous studies have demonstrated that DA transmission increases in a dose-dependent fashion after administration of natural (THC), synthetic (WIN-55212), or endogenous (anandamide) cannabinoids and that this stimulation of DA in the NAC shell peaks at about $50 \%$ over basal levels. The doses used in these previous studies are comparable to those used in our study $(49,50$, $52,72)$ but they were accompanied by higher rates of SA behavior $(39,63,64)$. In the present study, we did not observe a similar effect most likely due to the chemically unstable nature of 2-AG that quickly converts to $1-A G(38,73)$. This, together with MAGL activity, could be responsible for the lack of high brain levels of 2-AG. Notably, in the present study, these properties of 2-AG were carefully taken into consideration during the preparation of the solutions for iv administration; $2 \mathrm{AG}$ content in administered solutions was determined daily before microdialysis or SA sessions by HPLC-MS/MS analysis.

Even though the rate of responding and DA stimulation were lower for 2-AG than those observed after administration of common drugs of abuse, our study demonstrates that the eCB system stimulation, via the mesolimbic DA system (microdialysis experiments) or by 2-AG itself (SA experiments), encodes rewarding events. The present microdialysis data, however, show that passive administration as a single intravenous bolus of 2-AG increased DA levels in the NAc shell at doses of 5-10-fold higher than the 2-AG intake reached by rats during SA behavior. A possible explanation might be the sensitization of the effect of 2-AG on DA transmission in the NAc shell of animals chronically exposed to 
2-AG during the acquisition of 2-AG SA. Further experiments of SA coupled to microdialysis performed with the same experimental protocol previously published by our group (50) will serve to directly correlate the preferential increase of DA in the NAc shell to the 2-AG SA behavior observed in our experiments. On the other hand, the results obtained in 2-AG SA experiments may be also due to the food restriction regimen. Many studies show that the reduction of body weight by $20-25 \%$ dramatically enhances drug-induced SA (see (74) for review). Similarly, the suppression of natural growth used in the present study, although not associated with loss of weight, may have increased the motivation for 2-AG, suggesting that 2-AG SA may not be crucial in standard condition (e.g., ad libitum access to food). If so, the decrease of active responding for $2-\mathrm{AG}$ after the administration of rimonabant could be also due to the appetite suppression induced by this drug (75).

Consistent with other studies $(40,52)$, the main significance of our findings is not that 2-AG may pose a risk of abuse liability, but that the activation of the $\mathrm{eCB}$ system together with the DA system may potentiate the reinforcing effects or the abuse potential of many drugs of abuse, supporting the hypothesis that an increase in $\mathrm{eCB}$ tone may be involved in drug-seeking behavior (76). Recent studies show that the manipulation of eCB levels in the brain can be selectively and successfully achieved by eCB clearance inhibitors $(2,77-79)$. Altogether, the above evidence from previous work, in conjunction with our current results, suggests that the eCB system plays a role in reward and reinforcement that makes it a good candidate as a therapeutic target in behavioral disturbances of motivation and reward.

\section{ACKNOWLEDGMENTS}

This study was supported by Fondazione Banco di Sardegna and the Ministero dell'Università e della Ricerca (MURST/MIUR).

\section{REFERENCES}

1. Pacher P, Bátkai S, Kunos G. The endocannabinoid system as an emerging target of pharmacotherapy. Pharmacol Rev (2006) 58(3):389-462. doi:10.1124/pr. 58.3.2

2. Ahn K, Johnson DS, Cravatt BF. Fatty acid amide hydrolase as a potential therapeutic target for the treatment of pain and CNS disorders. Expert Opin Drug Discov (2009) 4(7):763-84. doi:10.1517/17460440903018857

3. Di Marzo V. Endocannabinoids: synthesis and degradation. Rev Physiol Biochem Pharmacol (2008) 160:1-24. doi:10.1007/112_0505

4. Blankman JL, Cravatt BF. Chemical probes of endocannabinoid metabolism. Pharmacol Rev (2013) 65(2):849-71. doi:10.1124/pr.112.006387

5. Kirkham TC, Williams CM, Fezza F, Di Marzo V. Endocannabinoid levels in rat limbic forebrain and hypothalamus in relation to fasting, feeding and satiation: stimulation of eating by 2-arachidonoyl glycerol. Br J Pharmacol (2002) 136(4):550-7. doi:10.1038/sj.bjp.0704767

6. Piomelli D. More surprises lying ahead. The endocannabinoids keep us guessing. Neuropharmacology (2014) 76(Pt B):228-34. doi:10.1016/j.neuropharm.2013. 07.026

7. Sugiura T, Kodaka T, Kondo S, Tonegawa T, Nakane S, Kishimoto S, et al. 2-Arachidonoylglycerol, a putative endogenous cannabinoid receptor ligand, induces rapid, transient elevation of intracellular free $\mathrm{Ca} 2+$ in neuroblastoma $\times$ glioma hybrid NG108-15 cells. Biochem Biophys Res Commun (1996) 229(1):58-64. doi:10.1006/bbrc.1996.1757

8. Gonsiorek W, Lunn C, Fan X, Narula S, Lundell D, Hipkin RW. Endocannabinoid 2-arachidonyl glycerol is a full agonist through human type 2 cannabinoid receptor: antagonism by anandamide. Mol Pharmacol (2000) 57(5):1045-50.
9. Hillard CJ. Biochemistry and pharmacology of the endocannabinoids arachidonylethanolamide and 2-arachidonylglycerol. Prostaglandins Other Lipid Mediat (2000) 61(1-2):3-18.

10. Sugiura T, Kobayashi Y, Oka S, Waku K. Biosynthesis and degradation of anandamide and 2-arachidonoylglycerol and their possible physiological significance. Prostaglandins Leukot Essent Fatty Acids (2002) 66(2-3):173-92. doi:10.1054/plef.2001.0356

11. Alger BE, Kim J. Supply and demand for endocannabinoids. Trends Neurosci (2011) 34(6):304-15. doi:10.1016/j.tins.2011.03.003

12. Howlett AC, Reggio PH, Childers SR, Hampson RE, Ulloa NM, Deutsch DG. Endocannabinoid tone versus constitutive activity of cannabinoid receptors. Br J Pharmacol (2011) 163(7):1329-43. doi:10.1111/j.1476-5381.2011. 01364.x

13. Lupica CR, Riegel AC, Hoffman AF. Marijuana and cannabinoid regulation of brain reward circuits. Br J Pharmacol (2004) 143(2):227-34. doi:10.1038/sj.bjp. 0705931

14. Adermark L, Lovinger DM. Retrograde endocannabinoid signaling at striatal synapses requires a regulated postsynaptic release step. Proc Natl Acad Sci U S A (2007) 104(51):20564-9. doi:10.1073/pnas.0706873104

15. Howlett AC. Cannabinoid receptor signaling. Handb Exp Pharmacol (2005) 168:53-79. doi:10.1007/3-540-26573-2_2

16. Murataeva N, Straiker A, Mackie K. Parsing the players: 2-arachidonoylglycerol synthesis and degradation in the CNS. Br J Pharmacol (2014) 171(6):1379-91. doi:10.1111/bph.12411

17. Dinh TP, Carpenter D, Leslie FM, Freund TF, Katona I, Sensi SL, et al. Brain monoglyceride lipase participating in endocannabinoid inactivation. Proc Natl Acad Sci U S A (2002) 99(16):10819-24. doi:10.1073/pnas.152334899

18. Gulyas AI, Cravatt BF, Bracey MH, Dinh TP, Piomelli D, Boscia F, et al. Segregation of two endocannabinoid-hydrolyzing enzymes into pre- and postsynaptic compartments in the rat hippocampus, cerebellum and amygdala. Eur J Neurosci (2004) 20(2):441-58. doi:10.1111/j.1460-9568.2004.03428.x

19. Long JZ, Nomura DK, Cravatt BF. Characterization of monoacylglycerol lipase inhibition reveals differences in central and peripheral endocannabinoid metabolism. Chem Biol (2009) 16(7):744-53. doi:10.1016/j.chembiol.2009.05.009

20. Blankman JL, Simon GM, Cravatt BF. A comprehensive profile of brain enzymesthat hydrolyze the endocannabinoid 2-arachidonoylglycerol. Chem Biol (2007) 14(12):1347-56. doi:10.1016/j.chembiol.2007.11.006

21. Fu J, Bottegoni G, Sasso O, Bertorelli R, Rocchia W, Masetti M, et al. A catalytically silent FAAH-1 variant drives anandamide transport in neurons. Nat Neurosci (2012) 15(1):64-9. doi:10.1038/nn.2986

22. Maldonado R, Berrendero F, Ozaita A, Robledo P. Neurochemical basis of cannabis addiction. Neuroscience (2011) 181:1-17. doi:10.1016/j.neuroscience. 2011.02.035

23. Sidhpura N, Parsons LH. Endocannabinoid-mediated synaptic plasticity and addiction-related behavior. Neuropharmacology (2011) 61(7):1070-87. doi:10. 1016/j.neuropharm.2011.05.034

24. Sipe JC, Chiang K, Gerber AL, Beutler E, Cravatt BF. A missense mutation in human fatty acid amide hydrolase associated with problem drug use. Proc Natl Acad Sci U S A (2002) 99(12):8394-9. doi:10.1073/pnas.082235799

25. Chiang KP, Gerber AL, Sipe JC, Cravatt BF. Reduced cellular expression and activity of the P129T mutant of human fatty acid amide hydrolase: evidence for a link between defects in the endocannabinoid system and problem drug use. Hum Mol Genet (2004) 13(18):2113-9. doi:10.1093/hmg/ddh216

26. Kogan NM, Mechoulam R. Cannabinoids in health and disease. Dialogues Clin Neurosci (2007) 9(4):413-30.

27. Ledent C, Valverde O, Cossu G, Petitet F, Aubert JF, Beslot F, et al. Unresponsiveness to cannabinoids and reduced addictive effects of opiates in CB1 receptor knockout mice. Science (1999) 283(5400):401-4. doi:10.1126/science.283. 5400.401

28. Hungund BL, Szakall I, Adam A, Basavarajappa BS, Vadasz C. Cannabinoid CB1 receptor knockout mice exhibit markedly reduced voluntary alcohol consumption and lack alcohol-induced dopamine release in the nucleus accumbens. J Neurochem (2003) 84(4):698-704. doi:10.1046/j.1471-4159.2003. 01576.x

29. Houchi H, Babovic D, Pierrefiche O, Ledent C, Daoust M, Naassila M. CB1 receptor knockout mice display reduced ethanol-induced conditioned place preference and increased striatal dopamine D2 receptors. Neuropsychopharmacology (2005) 30(2):339-49. doi:10.1038/sj.npp.1300568 
30. Caillé S, Parsons LH. SR141716A reduces the reinforcing properties of heroin but not heroin-induced increases in nucleus accumbens dopamine in rats. Eur J Neurosci (2003) 18(11):3145-9. doi:10.1111/j.1460-9568.2003.02961.x

31. Solinas M, Panlilio LV, Antoniou K, Pappas LA, Goldberg SR. The cannabinoid CB1 antagonist N-piperidinyl-5-(4-chlorophenyl)-1-(2,4-dichlorophenyl) -4methylpyrazole-3-carboxamide (SR-141716A) differentially alters the reinforcing effects of heroin under continuous reinforcement, fixed ratio, and progressive ratio. J Pharmacol Exp Ther (2003) 306(1):93-102. doi:10.1124/jpet.102. 047928

32. Colombo G, Orrù A, Lai $\mathrm{P}$, Cabras $\mathrm{C}$, Maccioni $\mathrm{P}$, Rubio $\mathrm{M}$, et al. The cannabinoid CB1 receptor antagonist, rimonabant, as a promising pharmacotherapy for alcohol dependence: preclinical evidence. Mol Neurobiol (2007) 36(1):102-12. doi:10.1007/s12035-007-0017-y

33. Mereu M, Tronci V, Chun LE, Thomas AM, Green JL, Katz JL, et al. Cocaineinduced endocannabinoid release modulates behavioral and neurochemical sensitization in mice. Addict Biol (2013). doi:10.1111/adb.12080

34. Schlosburg JE, Carlson BLA, Ramesh D, Abdullah RA, Long JZ, Cravatt BF, et al. Inhibitors of endocannabinoid-metabolizing enzymes reduce precipitated withdrawal responses in THC-dependent mice. AAPS J (2009) 11(2):342-52. doi:10.1208/s12248-009-9110-7

35. Ramesh D, Ross GR, Schlosburg JE, Owens RA, Abdullah RA, Kinsey SG, et al. Blockade of endocannabinoid hydrolytic enzymes attenuates precipitated opioid withdrawal symptoms in mice. J Pharmacol Exp Ther (2011) 339(1):173-85. doi:10.1124/jpet.111.181370

36. Viganò D, Grazia Cascio M, Rubino T, Fezza F, Vaccani A, Di Marzo $\mathrm{V}$, et al. Chronic morphine modulates the contents of the endocannabinoid, 2-arachidonoyl glycerol, in rat brain. Neuropsychopharmacology (2003) 28(6):1160-7. doi:10.1038/sj.npp.1300117

37. Caillé S, Parsons LH. Cannabinoid modulation of opiate reinforcement through the ventral striatopallidal pathway. Neuropsychopharmacology (2006) 31(4):804-13. doi:10.1038/sj.npp.1300848

38. Caillé S, Alvarez-Jaimes L, Polis I, Stouffer DG, Parsons LH. Specific alterations of extracellular endocannabinoid levels in the nucleus accumbens by ethanol, heroin, and cocaine self-administration. J Neurosci (2007) 27(14):3695-702. doi:10.1523/JNEUROSCI.4403-06.2007

39. Justinova Z, Solinas M, Tanda G, Redhi GH, Goldberg SR. The endogenous cannabinoid anandamide and its synthetic analog $\mathrm{R}(+)$-methanandamide are intravenously self-administered by squirrel monkeys. J Neurosci (2005) 25(23):5645-50. doi:10.1523/JNEUROSCI.0951-05.2005

40. Justinova Z, Yasar S, Redhi GH, Goldberg SR. The endogenous cannabinoid 2-arachidonoylglycerol is intravenously self-administered by squirrel monkeys. J Neurosci (2011) 31(19):7043-8. doi:10.1523/JNEUROSCI.6058-10.2011

41. Schultz W. Getting formal with dopamine and reward. Neuron (2002) 36(2):241-63. doi:10.1016/S0896-6273(02)00967-4

42. Di Chiara G, Bassareo V, Fenu S, De Luca MA, Spina L, Cadoni C, et al. Dopamine and drug addiction: the nucleus accumbens shell connection. Neuropharmacology (2004) 47(Suppl 1):227-41. doi:10.1016/j.neuropharm.2004.06.032

43. Wise RA. Dopamine and reward: the anhedonia hypothesis 30 years on. Neurotox Res (2008) 14(2-3):169-83. doi:10.1007/BF03033808

44. Di Chiara G. Brain dialysis of neurotransmitters: a commentary. J Neurosci Methods (1990) 34(1-3):29-34. doi:10.1016/0165-0270(90)90039-I

45. Pontieri FE, Tanda G, Di Chiara G. Intravenous cocaine, morphine, and amphetamine preferentially increase extracellular dopamine in the "shell" as compared with the "core" of the rat nucleus accumbens. Proc Natl Acad Sci U S A (1995) 92(26):12304-8. doi:10.1073/pnas.92.26.12304

46. Volkow ND, Wang G-J, Fowler JS, Molina PE, Logan J, Gatley SJ, et al. Cardiovascular effects of methylphenidate in humans are associated with increases of dopamine in brain and of epinephrine in plasma. Psychopharmacology (2003) 166(3):264-70. doi:10.1007/s00213-002-1340-7

47. Fillenz M. In vivo neurochemical monitoring and the study of behaviour. Neurosci Biobehav Rev (2005) 29(6):949-62. doi:10.1016/j.neubiorev.2005.02.003

48. Chang L, Haning W. Insights from recent positron emission tomographic studies of drug abuse and dependence. Curr Opin Psychiatry (2006) 19(3):246-52. doi:10.1097/01.yco.0000218594.46431.2

49. Tanda G, Pontieri FE, Di Chiara G. Cannabinoid and heroin activation of mesolimbic dopamine transmission by a common mul opioid receptor mechanism. Science (1997) 276(5321):2048-50. doi:10.1126/science.276.5321.2048

50. Lecca D, Cacciapaglia F, Valentini V, Di Chiara G. Monitoring extracellular dopamine in the rat nucleus accumbens shell and core during acquisition and maintenance of intravenous WIN 55,212-2 self-administration. Psychopharmacology (2006) 188(1):63-74. doi:10.1007/s00213-006-0475-3

51. Fadda P, Scherma M, Spano MS, Salis P, Melis V, Fattore L, et al. Cannabinoid self-administration increases dopamine release in the nucleus accumbens. Neuroreport (2006) 17(15):1629-32. doi:10.1097/01.wnr.0000236853.40221.8e

52. Solinas M, Justinova Z, Goldberg SR, Tanda G. Anandamide administration alone and after inhibition of fatty acid amide hydrolase (FAAH) increases dopamine levels in the nucleus accumbens shell in rats. J Neurochem (2006) 98(2):408-19. doi:10.1111/j.1471-4159.2006.03880.x

53. Diana M, Melis M, Muntoni AL, Gessa GL. Mesolimbic dopaminergic decline after cannabinoid withdrawal. Proc Natl Acad Sci US A (1998) 95(17):10269-73. doi:10.1073/pnas.95.17.10269

54. Tanda G, Loddo P, Di Chiara G. Dependence of mesolimbic dopamine transmission on delta9-tetrahydrocannabinol. Eur J Pharmacol (1999) 376(1-2):23-6. doi:10.1016/S0014-2999(99)00384-2

55. Paxinos G, Watson C. The Rat Brain in Stereotaxic Coordinates. 4th ed. London: Academic Press (1998)

56. Fattore L, Viganò D, Fadda P, Rubino T, Fratta W, Parolaro D. Bidirectional regulation of mu-opioid and $\mathrm{CB} 1$-cannabinoid receptor in rats selfadministering heroin or WIN 55,212-2. Eur J Neurosci (2007) 25(7):2191-200. doi:10.1111/j.1460-9568.2007.05470.x

57. Panlilio LV, Zanettini C, Barnes C, Solinas M, Goldberg SR. Prior exposure to THC increases the addictive effects of nicotine in rats. Neuropsychopharmacology (2013) 38(7):1198-208. doi:10.1038/npp.2013.16

58. Lecca D, Cacciapaglia F, Valentini V, Gronli J, Spiga S, Di Chiara G. Preferential increase of extracellular dopamine in the rat nucleus accumbens shell as compared to that in the core during acquisition and maintenance of intravenous nicotine self-administration. Psychopharmacology (2006) 184(34):435-46. doi:10.1007/s00213-005-0280-4

59. Chauvet C, Lardeux V, Goldberg SR, Jaber M, Solinas M. Environmental enrichment reduces cocaine seeking and reinstatement induced by cues and stress but not by cocaine. Neuropsychopharmacology (2009) 34(13):2767-78. doi:10.1038/npp.2009.127

60. Lecca D, Cacciapaglia F, Valentini V, Acquas E, Di Chiara G. Differential neurochemical and behavioral adaptation to cocaine after response contingent and noncontingent exposure in the rat. Psychopharmacology (2007) 191(3):653-67. doi:10.1007/s00213-006-0496-y

61. Lecca D, Valentini V, Cacciapaglia F, Acquas E, Di Chiara G. Reciprocal effects of response contingent and noncontingent intravenous heroin on in vivo nucleus accumbens shell versus core dopamine in the rat: a repeated sampling microdialysis study. Psychopharmacology (2007) 194(1):103-16. doi:10.1007/s00213007-0815-y

62. Fattore L, Spano M, Melis V, Fadda P, Fratta W. Differential effect of opioid and cannabinoid receptor blockade on heroin-seeking reinstatement and cannabinoid substitution in heroin-abstinent rats. Br J Pharmacol (2011) 163(7):1550-62. doi:10.1111/j.1476-5381.2011.01459.x

63. Tanda G, Munzar P, Goldberg SR. Self-administration behavior is maintained by the psychoactive ingredient of marijuana in squirrel monkeys. Nat Neurosci (2000) 3(11):1073-4. doi:10.1038/80577

64. Justinova Z, Tanda G, Redhi GH, Goldberg SR. Self-administration of delta9tetrahydrocannabinol (THC) by drug naive squirrel monkeys. Psychopharmacology (2003) 169(2):135-40. doi:10.1007/s00213-003-1484-0

65. Justinova Z, Mangieri RA, Bortolato M, Chefer SI, Mukhin AG, Clapper JR, et al. Fatty acid amide hydrolase inhibition heightens anandamide signaling without producing reinforcing effects in primates. Biol Psychiatry (2008) 64(11):930-7. doi:10.1016/j.biopsych.2008.08.008

66. Wise RA. Drug-activation of brain reward pathways. Drug Alcohol Depend (1998) 51(1-2):13-22. doi:10.1016/S0376-8716(98)00063-5

67. Wise RA. Brain reward circuitry: insights from unsensed incentives. Neuron (2002) 36(2):229-40. doi:10.1016/S0896-6273(02)00965-0

68. Di Chiara G. Nucleus accumbens shell and core dopamine: differential role in behavior and addiction. Behav Brain Res (2002) 137(1-2):75-114. doi:10.1016/ S0166-4328(02)00286-3

69. Wenger T, Ledent C, Tramu G. The endogenous cannabinoid, anandamide, activates the hypothalamo-pituitary-adrenal axis in CB1 cannabinoid receptor knockout mice. Neuroendocrinology (2003) 78(6):294-300. doi:10.1159/ 000074882

70. Melis M, Pistis M, Perra S, Muntoni AL, Pillolla G, Gessa GL. Endocannabinoids mediate presynaptic inhibition of glutamatergic transmission in rat ventral 
tegmental area dopamine neurons through activation of CB1 receptors. J Neurosci (2004) 24(1):53-62. doi:10.1523/JNEUROSCI.4503-03.2004

71. Marinelli S, Di Marzo V, Florenzano F, Fezza F, Viscomi MT, van der Stelt M, et al. $\mathrm{N}$-arachidonoyl-dopamine tunes synaptic transmission onto dopaminergic neurons by activating both cannabinoid and vanilloid receptors. Neuropsychopharmacology (2007) 32(2):298-308. doi:10.1038/sj.npp.1301118

72. De Luca MA, Solinas M, Bimpisidis Z, Goldberg SR, Di Chiara G. Cannabinoid facilitation of behavioral and biochemical hedonic taste responses. Neuropharmacology (2012) 63(1):161-8. doi:10.1016/j.neuropharm.2011.10.018

73. Rouzer CA, Ghebreselasie K, Marnett LJ. Chemical stability of 2arachidonylglycerol under biological conditions. Chem Phys Lipids (2002) 119(1-2):69-82. doi:10.1016/S0009-3084(02)00068-3

74. Carr KD. Augmentation of drug reward by chronic food restriction: behavioral evidence and underlying mechanisms. Physiol Behav (2002) 76(3):353-64. doi:10.1016/S0031-9384(02)00759-X

75. McLaughlin PJ, Winston K, Swezey L, Wisniecki A, Aberman J, Tardif DJ, et al. The cannabinoid CB1 antagonists SR141716A and AM 251 suppress food intake and food-reinforced behavior in a variety of tasks in rats. Behav Pharmacol (2003) 14(8):583-8. doi:10.1097/00008877-200312000-00002

76. Gutierrez-Lopez MD, Llopis N, Feng S, Barrett DA, O’Shea E, Colado MI. Involvement of 2-arachidonoyl glycerol in the increased consumption of and preference for ethanol of mice treated with neurotoxic doses of methamphetamine. Br J Pharmacol (2010) 160(3):772-83. doi:10.1111/j.1476-5381.2010. 00720.x

77. Fowler CJ. "The tools of the trade" - an overview of the pharmacology of the endocannabinoid system. Curr Pharm Des (2008) 14(23):2254-65. doi:10.2174/138161208785740126
78. Petrosino S, Ligresti A, Di Marzo V. Endocannabinoid chemical biology: a tool for the development of novel therapies. Curr Opin Chem Biol (2009) 13(3):309-20. doi:10.1016/j.cbpa.2009.04.616

79. Wiskerke J, Irimia C, Cravatt BF, De Vries TJ, Schoffelmeer ANM, Pattij T, et al. Characterization of the effects of reuptake and hydrolysis inhibition on interstitial endocannabinoid levels in the brain: an in vivo microdialysis study. ACS Chem Neurosci (2012) 3(5):407-17. doi:10.1021/cn300036b

Conflict of Interest Statement: The authors declare that the research was conducted in the absence of any commercial or financial relationships that could be construed as a potential conflict of interest.

Received: 19 July 2014; accepted: 23 September 2014; published online: 17 October 2014.

Citation: De Luca MA, Valentini V, Bimpisidis Z, Cacciapaglia F, Caboni P and Di Chiara $G$ (2014) Endocannabinoid 2-arachidonoylglycerol self-administration by Sprague-Dawley rats and stimulation of in vivo dopamine transmission in the nucleus accumbens shell. Front. Psychiatry 5:140. doi: 10.3389/fpsyt.2014.00140

This article was submitted to Neuropharmacology, a section of the journal Frontiers in Psychiatry.

Copyright $(2014$ De Luca, Valentini, Bimpisidis, Cacciapaglia, Caboni and Di Chiara. This is an open-access article distributed under the terms of the Creative Commons Attribution License (CC BY). The use, distribution or reproduction in other forums is permitted, provided the original author(s) or licensor are credited and that the original publication in this journal is cited, in accordance with accepted academic practice. No use, distribution or reproduction is permitted which does not comply with these terms. 